\title{
NON HODGKIN'S LYMPHOMA OF STOMACH WITH SPONTANEOUS PERFORATION: A CASE REPORT WITH REVIEW OF LITERATURE
}

\author{
Rishikant Vashistha' ${ }^{1}$, Abhishek Kansal'2, S.M. Datey ${ }^{3}$, Vikramaditya Singh ${ }^{4}$
}

\section{HOW TO CITE THIS ARTICLE:}

Rishikant Vashistha, Abhishek Kansal, S.M. Datey, Vikramaditya Singh. "Non-Hodgkin's Lymphoma of Stomach with Spontaneous Perforation: A Case Report with Review of Literature". Journal of Evolution of Medical and Dental Sciences 2014; Vol. 3, Issue 03, January 20; Page: 660-664, DOI: 10.14260/jemds/2014/1882

\begin{abstract}
Stomach is the commonest extranodal site of lymphomas. A case of Non-Hodgkin's Lymphoma of stomach is reported here for its unusual way of presentation. Fifty year old male presented with features of perforation peritonitis, which on exploration turned out to be a NonHodgkin's lymphoma of stomach with perforation. Usually gastric lymphomas are diagnosed on upper gastrointestinal endoscopic examination and biopsy in patients with epigastric pain, early satiety and weight loss. Detailed review of literature denotes that spontaneous perforation in a case of lymphoma of the gastrointestinal tract is uncommon, although many cases of perforation after chemo or radiotherapy are reported.
\end{abstract}

KEYWORDS: Non Hodgkin's Lymphoma , Gastric Perforation

INTRODUCTION: Stomach is the commonest extranodal site of gastric lymphomas. In a series of Non-Hodgkin's Lymphomas $15 \%$ to $20 \%$ cases had involvement of the stomach ${ }^{1}$.Gastric lymphoma commonly affects those over 60 years of age and is commonly seen in males. Common symptoms include epigastric pain, early satiety, easy fatigability and significant weight loss. Gastric lymphoma is commonly diagnosed on upper GI endoscopy for these symptoms. Rarely it can present due to a complication like upper gastrointestinal hemorrhage or perforation.

We are presenting a case of a 50 year old male who was operated in emergency for perforation peritonitis. Exploratory laparotomy revealed perforation in the anterior wall of stomach with an indurated mass. This perforation was repaired after taking multiple biopsies from the edges. Histopathological examination of the biopsies revealed a Non-Hodgkin's Lymphoma of stomach. The case is presented with review of literature as spontaneous perforation of a gastric lymphoma is an uncommon clinical entity.

CASE REPORT: Fifty year male presented with complaints of severe epigastric pain, vomiting and distended abdomen of two days duration. He was Haemodynamically stable with generalized guarding and rigidity of abdomen and peristaltic sounds were absent. Erect x-ray of abdomen showed presence of free gas under the right dome of diaphragm and generalized haziness all over abdomen suggestive of perforation of a hollow viscus with peritonitis. Ultrasound examination showed collection of more than $500 \mathrm{ml}$ free fluid in the abdominal cavity. All other investigations were within normal limits except for a marked polymorphonuclear leukocytosis. Patient was subjected to an exploratory laparotomy by an

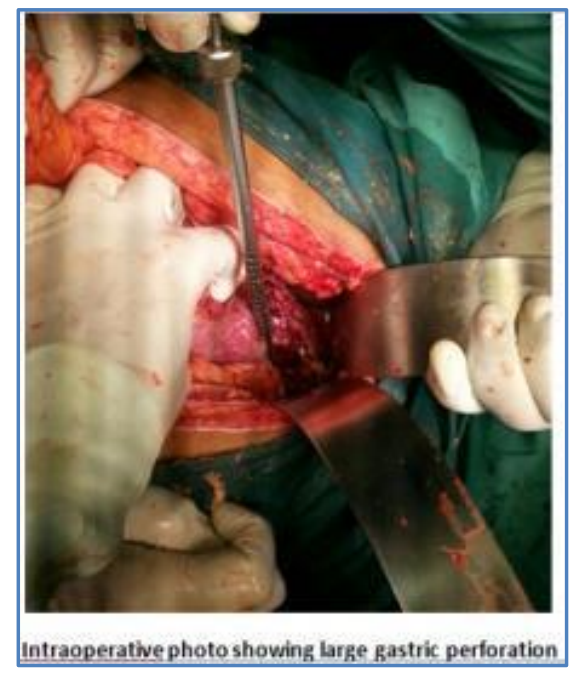


upper midline incision with a probable diagnosis of a peptic perforation. On exploration peritoneal cavity was filled with purulent fluid. Anterior wall of stomach showed a big perforation of $5 \mathrm{~cm} \mathrm{X}$ $7 \mathrm{~cm}$. Margins of this perforation were indurated and a growth could be palpated in the anterior wall of stomach near the greater curvature. Multiple biopsies were taken from the edges of the perforation. Defect was repaired and an omental patch applied. Abdominal wound closed after a thorough peritoneal lavage, a feeding jejunostomy and placement of abdominal drains.

Histopathology of the biopsies showed that the lesion from the stomach wall was a Non-Hodgkin's Lymphoma. Postoperative CECT scan of the abdomen revealed the involvement of many lymph nodes of para-aortic and peri-gastric groups. Postoperative recovery was not smooth and was marked by pulmonary complications and abdominal wound dehiscence which needed a secondary repair. Patient was referred to oncology for further management with chemo and radiotherapy.

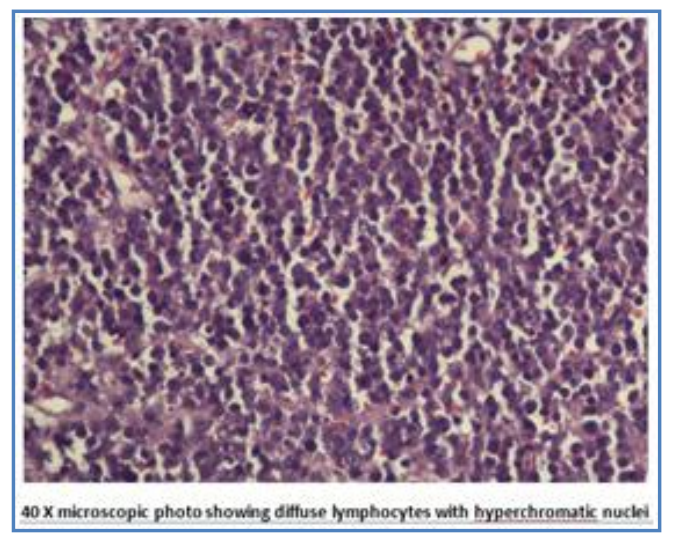

\section{REVIEW OF LITERATURE:}

\section{GASTRIC LYMPHOMA:}

INCIDENCE: Primary gastric lymphomas are uncommon and account for $2 \%$ to $8 \%$ of all malignancies of the stomach ${ }^{2-5}$. Recent studies show that the incidence of gastric lymphomas is increasing over the last two decades ${ }^{6}$. Two fold increase has been reported in the age adjusted incidence of gastric lymphoma on the basis of data from the Surveillance, Epidemiology and End Result Program (SEER) 6. Stomach is the most common extranodal site of Non-Hodgkin's lymphomas. In a series of Non-Hodgkin's lymphomas $15 \%$ to $20 \%$ were gastric lymphomas ${ }^{1}$. Gastric lymphomas are commonly seen in males after the age of 60 years.

PATHOLOGY: Gastric lymphoma starts from the submucosal layer of the stomach wall as it has the lymphoid tissue. Lymphoid tissue from the lamina propria leads to formation of polypoidal masses. Proliferation leads to invasion of the serosal layer in the beginning and later to the mucosa, forming small ulcerative lesions. The lesion can be single or can be multifocal. Size of the lesion varies and it can as big as $10 \mathrm{cms}$. In few cases the disease can be of diffuse variety and involves the whole of stomach and simulates the linitis plastica. Organs in vicinity of stomach i.e. pancreas, spleen and omentum are involved in more than $30 \%$ of cases of Non-Hodgkin's Lymphoma. Colon and small intestine are rarely involved.

MICROSCOPIC FEATURES: Non-Hodgkin's lymphoma is characterized by the presence of lymphoepithelial lesions with lymphoid follicles and plasma cellular infiltration. The cells resemble centrocytes with small, dense, granular nuclei with clear cytoplasm and irregular borders. Chronic inflammation and immunostimulation could precede the polymicrobial lymphocyte proliferation until one clone acquires malignant properties and lymphoma develops.

Histologically gastric lymphomas are divided in four groups ${ }^{7}$. 


\section{HISTLOGICAL CLASSIFICATION:}

\begin{tabular}{|c|c|c|}
\hline Low Grade & $\begin{array}{c}\text { LG } \\
\text { MALT-L }\end{array}$ & $\begin{array}{c}\text { Dense infiltrate of marginal zone cells } \\
\text { and lymphoepithelial lesions(LELs) }\end{array}$ \\
\hline Low grade/high grade & $\begin{array}{c}\text { LG/HG } \\
\text { MALT-L }\end{array}$ & $\begin{array}{c}\text { Large, transformed cells with } \\
\text { evidence of low grade MALT-L }\end{array}$ \\
\hline High Grade & HG MALT-L & $\begin{array}{c}\text { Large, transformed cells with destruction } \\
\text { of gastric epithelium and pits formation }\end{array}$ \\
\hline Diffuse & DLCL & $\begin{array}{c}\text { Diffuse large cells without a follicular pattern, } \\
\text { and infiltrating the submucosa and epithelium }\end{array}$ \\
\hline
\end{tabular}

ROLE OF HELICOBACTER PYLORI: Mucosa Associated Lymphoid Tissue (MALT) lymphomas are demonstrated to be closely associated with Helicobacter Pylori (HP) infection. A series in 1994 found that HP infection was present in $92 \%$ of patients with primary gastric lymphomas ${ }^{8}$. Regression of gastric lymphomas is described after eradication of Helicobacter Pylori infection. HP reinfection is associated with recurrence of gastric lymphoma and for this reason a long term follow up of patient is necessary.

STAGING: This staging was described after the Fifth International Conference on Malignant Lymphomas ${ }^{7}$.

I. Limited to gastrointestinal tract.

II. Extending into abdomen from the primary site.

a. Local nodal involvement (perigastric/mesenteric)

b. Distant nodal involvement (paraaortic/paracaval)

III. Penetration of serosa to involve adjacent structures.

IV. Disseminated disease or Supradiphragmatic nodal involvement.

CLINICAL SIGNS AND DIAGNOSIS: Gastric lymphomas can have various symptoms which are mainly related to upper gastrointestinal tract. Epigastric pain, early satiety, anorexia and weight loss are the commonest symptoms for which a patient seeks advice. Gastric lymphomas are commonly seen in sixth decade of life and are common in males. A small number of patients can be asymptomatic. Symptoms are due to progressive narrowing of the gastric lumen due thickening of wall because of the proliferation of lymphoid tissue and loss of rugal folds. Diagnosis is done by an endoscopic biopsy. Endoscopy demonstrates diffuse infiltrative process with thick non-pliable folds, ulcerative lesions and polypoidal masses. Barium study shows lesion in $75 \%$ of cases with enlarged gastric folds and loss of rugosities. Imaging studies like Contrast Enhanced Computerized Tomography (CECT), Spiral CT or MRI are mandatory to show the perigastric spread and extent of disease.

TREATMENT: It is still discussed as which modality is better for gastric lymphoma. Chemoradiation and surgery are both good options. As the disease is infrequent hence the studies do not have significant number of cases to support either modality as the most appropriate treatment and prospective randomized studies are difficult. Importantly Gastric MALT Lymphoma is often 
associated with Helicobacter Pylori infection, and, is frequently treated by eradication of the organism.

CASE DISCUSSION: Spontaneous perforation of stomach due to a lymphoma is an uncommon clinical entity. Shimada s et al have reported spontaneous gastric perforation in a case of malignant gastric lymphoma and stated in their article that gastric lymphoma with spontaneous perforation has been reported in Japanese literature only 26 times in last 25 years ${ }^{9}$. Another series evaluated eight cases of intestinal perforations due to lymphoma, out of which six were spontaneous and located in small and large bowel ${ }^{10}$. Three out of eight were repaired primarily while in four a resection anastomosis was done. Perforation of sigmoid was managed by a colostomy. Surgical treatment options are limited to either a closure of perforation with biopsy or a local resection if histological evidence of a malignant tumor is available. General condition of these patients may be critical due to overwhelming sepsis and poor nutritional status. Patient can be subjected to adjuvant chemotherapy on receiving the tissue diagnosis of lymphoma after getting over the problem of critical abdominal sepsis. A case of gastric lymphoma with spontaneous perforation with peritonitis has been reported in the literature in which preoperative diagnosis of lymphoma was done11. They did an endoscopic examination of the stomach which revealed a perforated gastric tumor in the lower part of body on the greater curvature. A subtotal gastrectomy was done which showed Gastric B-cell lymphoma of diffuse, medium sized cell type. Postoperatively adjuvant chemotherapy was given with Cyclophospamide, Doxorubicin, Vincristine and Prednisolone (CHOP regimen) with good results. CT scanning is more frequently done in the evaluation of acute abdomen nowadays and many cases can be diagnosed and resection can be done by reaching a diagnosis preoperatively by upper GI endoscopy. We have presented this case because it is an unusual presentation of a comparatively uncommon disease.

\section{BIBILOGRAPHY:}

1. Schutze KP et al. Gastric Lymphoma. Surg Gynecol Obstet. (1991); 172:33-38.

2. Sandler RS. Primary gastric Lymphoma: a review. Am J Gastroenterol. (1984); 79(1):21-25.

3. Cogliatti SB, Schmid U, Schumacher $U$ et al. Primary B-cell Gastric Lymphoma: A clinicopathological study of 145 patients. Gastroenterology. (1991); 101:1159-1170.

4. Hayes J, Dunn E. Has the incidence of primary gastric lymphoma increased? Cancer (1989); 63:2073-2076.

5. Rosen CB, Van, Heerden JA, Martin JK et al. Is an aggressive surgical approach to a patient with gastric lymphoma warranted? Ann Surg (1987); 205(6):634-640.

6. Severson RK, Davis S. Increasing incidence of primary gastric lymphoma. Cancer. 1990 Sep 15; 66(6): 1283-7

7. Rohaitner A, Amre F, Coiffer B et al. Report of a workshop convened to discuss pathological and staging classifications of gastro intestinal tract lymphomas. Ann Oncol (1994); 5:397-400.

8. Wotherspoon AC, Doglioni C, Diss TC, Pan L, Moschini A, de Boni M, Issacson PG. Regression of Primary Low Grade B-Cell Gastric Lymphoma of mucosa associated lymphoid tissue type after eradication of Helicobacter Pylori: Lancet. 1993 Sep 4; 342 (8871): 575-7

9. Shimaada S, Gen T, Okamoto H. Malignant Gastric Lymphoma with spontaneous perforation. BMJ Case Rep; 2013 Jan: 17-20. 


\section{CASE REPORT}

10. Cengiz, Ara, Coban, Sacid, Kayaalp, Cuneyt et al. Spontaneous Intestinal Perforation due to NonHodgkin's Lymphoma: Evaluation of eight cases in Digestive Diseases and Sciences.(Aug 2007)52.8:1752-6.

11. Yabuki K, Tamasaki Y, Satoh K, Meakawa T, Matsumoto M. Primary Gastric lymphoma with spontaneous perforation: Report of a case. Surg Today.2000; 30(11): 1030-3.

\section{AUTHORS:}

1. Rishikant Vashistha

2. Abhishek Kansal

3. S.M. Datey

4. Vikramaditya Singh

\section{PARTICULARS OF CONTRIBUTORS:}

1. Assistant Professor, Department of General Surgery, Sri Aurobindo Medical College and Postgraduate Institute, Indore, India.

2. Assistant Professor, Department of General Surgery, Sri Aurobindo Medical College and Postgraduate Institute, Indore, India.

3. Professor, Department of General Surgery, Sri Aurobindo Medical College and Postgraduate Institute, Indore, India.
4. Resident, Department of General Surgery, Sri Aurobindo Medical College and Postgraduate Institute, Indore, India.

\section{NAME ADDRESS EMAIL ID OF THE} CORRESPONDING AUTHOR:

Dr. Rishikant Vashistha, 2 BB, Slice No. 5, Scheme No. 78, Vijay Nagar, Indore, (M.P) - 452010.

Email - vashistharishikant@gmail.com

Date of Submission: 27/12/2013.

Date of Peer Review: 28/12/2013.

Date of Acceptance: 08/01/2014.

Date of Publishing: 16/01/2014. 